Federal Reserve Bank of Minneapolis

Research Department Staff Report 389

April 2007

\title{
Does Regulation Reduce Productivity? Evidence From Regulation of the U.S. Beet-Sugar Manufacturing Industry During the Sugar Acts, 1934-74*
}

\author{
Benjamin Bridgman \\ Bureau of Economic Analysis
}

\section{Shi Qi}

Federal Reserve Bank of Minneapolis

and University of Minnesota

James A. Schmitz, Jr.

Federal Reserve Bank of Minneapolis

\begin{abstract}
We study the impact of regulation on productivity and welfare in the U.S. sugar manufacturing industry. While this U.S. industry has been protected from foreign competition for nearly 150 years, it was regulated only during the Sugar Act period, 1934-74. We show that regulation significantly reduced productivity, with these productivity losses leading to large welfare losses. Our initial results indicate that the welfare losses are many times larger than those typically studied - those arising from higher prices. We also argue that the channels through which regulation led to large productivity and welfare declines in this industry were also present in many other regulated industries, like banking and trucking.
\end{abstract}

\footnotetext{
${ }^{*}$ We would like to thank Sam Kortum for his very helpful comments as a discussant at the Minnesota Micro Conference in October 2006. We would also like to thank the large number of people in the industry that provided help, especially Charles Schmalz, who worked for both the Utah\&Idaho and Amalgamated Sugar Companies; Dennis Costesso of Amalgamated Sugar Company; and James Horvath and Dave Malmskog from the American Crystal Sugar Company. Finally, we would like to acknowledge the help from archivists of numerous libraries (to be listed in the next version) across the country. The views expressed herein are those of the authors and not necessarily those of the Federal Reserve Bank of Minneapolis, the Federal Reserve System, the U.S. Bureau of Economic Analysis or the U.S. Department of Commerce.
} 


\section{Introduction}

Most studies of the economic impact of regulation focus on industry prices. When an industry is regulated, competition is often dramatically curtailed, so there is good reason to expect higher industry prices. And most studies find this. But there are also good reasons (described shortly) to expect industry productivity to suffer as well. And while economic welfare or surplus losses from higher prices are typically small, those from productivity losses may be many orders of magnitude larger. Hence, it's important to also study regulation's impact on productivity, and how productivity losses translate into surplus losses.

We study the impact of regulation on productivity in the U.S. sugar manufacturing industry. Sugar manufacturing is a two-step process: farmers produce crops (sugarbeets or sugarcane) that are then processed in nearby factories. While this U.S. industry has been protected from foreign competition for nearly 150 years, it was regulated only during the Sugar Act period, 1934-74. There are two key channels through which regulation adversely influenced productivity in this industry. First, regulation dramatically reduced domestic competition. Factories were given sales quotas and farmers were given acreage quotas. Given producers were told how much they could sell, there was very little competition, and lack of competition has been shown to reduce productivity. In this paper we do not, in fact, study this channel. Rather, our focus is on the second channel. For "voluntarily" abiding by acreage quotas, farmers were given subsidies by the government based on their "output." To cover these subsidies, the factories were taxed on the sugar they produced. The rationale for these regulatory provisions was to insure "fair-division" of the benefits (among producer groups) of

the sugar program. Tax/subsidy schemes can obviously distort production decisions and, like lack of competition, reduce productivity.

We find the fair-division provisions, by distorting production decisions, led to very significant productivity declines. And we find the productivity declines led to large welfare losses (though these results are preliminary). 
To understand the impacts of the fair-division provisions, we need a few details. The farms produce beets, say $T$ tons, that contain sugar. We call this sugar, sugar-in-the-crop, and denote it $S$ (obviously, $S<T$ ). Factories took the beets and extracted the sugar $S$, producing the final output, or sugar-in-the-bag, which we denote $Y$ (again, $Y<S$ ). The fair-division provisions called for farmers to receive subsidies for the $S$ they produced. To pay for the subsidies, factories were taxed on $Y$.

What was the impact of these provisions, of the subsidy/tax scheme? Think of the farms and factory as an integrated operation. ${ }^{1}$ The subsidy/tax scheme led to many distortions in production. First, when farming before the subsidy to sugar-in-the crop $S$, the operation worried about how easily the sugar-in-the-crop could be extracted to make $Y$. Now, the operation was less worried about extraction because the operation was paid for sugar-in-the-crop $S$ as well as $Y$. As we'll show, this leads to a change in farming practices, in particular, a change in the mix of farm inputs, with a more intensive use of irrigation and fertilizer per unit of farm land. Quality of the beets, that is, their sugar content, $q=S / T$, falls.

Another distortion is that the "scale" of factory inputs relative to farm inputs fell. Because of the subsidy to $S$, the operation increases farm inputs. In our model, factory inputs are not scaled up to the same extent as farm inputs because of the tax on $Y$. Hence, factory inputs increase less than farm inputs. This means the extraction rate of sugar, $Y / S$, falls.

These distortions, the change in farming practices, and the decrease in factory inputs relative to farm, will have productivity consequences. These consequences are easily seen in the data. One (partial) productivity measure that is commonly used in this industry is the recovery rate, that is, the pounds of sugar $Y$ produced per ton of beets $T$, or $Y / T$. The recovery rate is the product of beet quality $q=S / T$ and the extraction rate $Y / S$. We have argued that both $q$ and $Y / S$ would

\footnotetext{
${ }^{1}$ Most operations were not integrated, and factories purchased beets from farmers on the basis of contracts signed before the season opened. But a similar analysis applies in this case. See more discussion below.
} 
fall, so the recovery rate certainly should.

At the national level, the recovery rate increased from the beginning of the 20th century until 1934, then decreased steadily until 1974, at which point it then began to grow again (see Figure 1). Hence, there is certainly a very close association between the recovery rate and the Sugar Acts. And the changes were big. More than 300 pounds of sugar were recovered from a ton of beets at the beginning of the Sugar Act and less than 250 pounds at the finish. We have collected data on recovery rates for each of the major companies, and for many of these companies, we have their individual factory data as well. The pattern seen at the national level (Figure 1) shows up in every company, and nearly every factory. Moreover, the decline in the recovery rate was typically much larger at individual factories (as we'll see below). That is because during the Sugar Act period production shifted toward high recovery rate areas (like California). We'll also show that recovery rates were not falling in Europe during the Sugar Act period.

We'll also briefly discuss other productivity measures, like TFP, and show that they fell during the Sugar Act period.

Let's now turn from productivity to discuss the fair-division provisions' impact on economic surplus. The provisions reduced producer surplus. In particular, let $V$ denote total producer surplus under the Sugar Act regulations except the fair-division provisions. Let $V_{R}$ denote total producer surplus under all Sugar Act regulations (i.e., including the fair-division provisions). Then, under the assumption that taxes cover subsidies, it's easy to prove in our model that $V_{R}<V$. Moreover, our quantitative results, though preliminary, indicate that the percentage loss in producer surplus from the fair-division scheme, $1-\left[V_{R} / V\right]$, is quite large. At the start of the Sugar Act in the late 1930s, subsidies and taxes averaged about $20 \%$ of industry revenues. After WWII, both subsidies and taxes fell as a share of industry revenues. Subsidies were about $10 \%$ of industry revenues, and taxes about $5 \%$. If we have a 10\% subsidy rate in our calibrated model (and balance the budget), producer surplus falls by $25 \%$. 
Before proceeding to our formal model, we want to argue that the type of regulatory provisions we just discussed in the sugar industry was typically present in most U.S. regulated industries, from banking to trucking. As Stigler (1971) argued, the impetus for regulation is often to limit competition (the first channel through which regulation reduces productivity). But, as Stigler (1971) also argued, insiders do not speak with one voice. Once an industry uses the political process to limit competition, some producer groups with more political power may insert additional regulatory provisions to shift the benefits of reduced competition their way (the second channel). In the sugar industry, these were the fair-division provisions. In the banking industry, banks succeeded in blocking competition from outsiders (like investment banks), yet industry insiders (e.g., small banks) were able to insert regulations requiring all banks to have only a single branch. These provisions shifted the benefits of reduced competition from urban to small-town banks. In trucking, regulations requiring that firms have certificates to move goods in each direction often meant trucks traveled empty in one direction. These certificates obviously shifted the benefits of reduced competition from firms contemplating expanding into the city-pair to incumbents in a city-pair (that had rights to carry goods both ways).

So, the regulatory provisions we discuss in the sugar industry were present in many U.S. regulated industries. Hence, it is possible that these provisions in other industries led to significant welfare losses too, losses many times larger than the losses from higher prices and Harberger triangles. One-branch banking was a significant restriction on technology. Having trucks travel empty one-way because the firm was unable to get a certificate is also a significant restriction on technology.

As mentioned, most studies of the economic impact of regulation focus on industry prices (see for example, Crawford (2000), Goolsbee and Petrin (2004), MacDonald and Cavalluzzo (1996), and Ying and Keeler (1991)). Studies that have looked at regulation's impact on factor choices and productivity include Acemoglu and Finkelstein (2006), Markiewicz, Rose and Wolfram (2007), and Olley and Pakes (1996).

The outline of the paper is as follows. In the next section, we present more background on 
the industry regulations and (aggregate) productivity during the Sugar Act period. In Section 3, we introduce a simple model that we will use to analyze the impact of regulation. In Section 4, we begin our analysis of regulation, asking how the redistribution (i.e., fair-division) scheme influenced industry productivity. In Section 5, we look at productivity at the company and factory level. In Section 6, we again return to the model, asking how the redistribution scheme influenced producer surplus.

\section{Overview of Regulation and Productivity}

Here we add a few more details about industry regulation. Then we present some aggregate productivity statistics as a way to motivate the development of the model.

U.S. sugar supplies come from both domestic and foreign sources. There are two domestic sources of U.S. sugar: sugar beets and sugar cane. In this paper, we concentrate on the domestic beet sugar industry. (We examine the cane industry in a separate paper.) Sugar beets are grown on farms throughout the United States, from California to Michigan. After the beets are harvested, they are transported to factories that process them into refined (white) sugar. Since beets are bulky and decay quickly once harvested, the factories are located in beet growing areas.

\section{A. Regulation}

From its beginnings in the 1870s until 1934, the U.S. government's role in the sugarbeet industry was simple: it set a tariff that protected the industry. There was no domestic regulation of the industry. ${ }^{2}$ Government involvement in the industry dramatically changed in 1934 . First, the United States moved from a tariff on foreign sugar to foreign quotas. Second, the United States moved from no domestic regulation of industry to extensive regulation under the Sugar Acts (that would last 40 years).

As mentioned, there were two main features of domestic regulation. First, domestic produc-

\footnotetext{
${ }^{2}$ This is a bit of an overstatement, as during WWI the government was involved in the industry. Also, some U.S. states gave start-up subsidies to factories in the 1890's.
} 
tion was controlled. Sugar manufacturing firms were given marketing allotments. They could not sell more than these allotments. Still, as another way to control supply, farmers were given acreage allotments stating how many acres they could devote to beets. ${ }^{3}$ Second, programs were begun to shift some of the benefits of regulation toward some groups (e.g., farmers and field workers) and away from other groups (e.g., the factories).

To give a bit more detail as to how the control of sugar supplies worked, each year the government set a sugar sales-target for the year (sometimes called the "consumption estimate"). It then used a formula to divvy this sales-target between foreign and domestic sources. Foreign quotas were used as subsidies to U.S. allies, most notably Cuba, and support to U.S. affiliates (like Hawaii). The domestic share of the sales-target was then divided between beet and cane sugar producers, and then the beet quota was divided among the beet manufacturing firms, and so on.

The Sugar Act expired in 1974. In that year, world sugar prices soared, and the coalition that had lobbied to end the Sugar Acts won the day. Protection from foreign sugar remained, in the form of quotas, and in fact, these quotas have fallen significantly in the post-1974 period. But domestic regulation has essentially ceased. U.S. sugar manufacturers are no longer subject to marketing allotments. The tax/subsidy scheme was abandoned. Given that there is no control of domestic sales, competition has increased. ${ }^{4}$

As mentioned, we will study only the second channel of regulation. But let us briefly comment on the first - the restraining of domestic competition. Since foreign sugar was subject to quota, the domestic price was decoupled from the world price. Because domestic manufacturing firms had fixed allotments, they had little incentive to cut price. Hence, domestic regulations kept prices high. This led to a distortion of too little output and a loss in economic surplus (consumer surplus) (i.e.,

\footnotetext{
${ }^{3}$ Though there was an elaborate procedure to keep track of how much land each farmer devoted to sugarbeets each year, farmers were not given explicit quotas in all years. Of course, since the factories were given allotments, the farmers in some sense were too (since factories did not want to have to store sugar). Factory allotments were not set in all years, but nearly all.

${ }^{4}$ Another development was the introduction of high fructose corn syrup in the late 1970's, which also increased competition.
} 
"Harberger" triangles). As mentioned, these are typically small losses.

But, of course, fixed factory-allotments dulled incentives to innovate. The economic return to finding better ways to manufacture sugar and hence lower costs were limited since firms had fixed allotments. This effect is present if there was only a single firm. But with more than one firm, fixed allotments reduce competition, an independent negative effect on productivity. The effect of fixed allotments on productivity and surplus may have been large. But as we said, we are primarily studying the fair-division provisions.

\section{B. Productivity}

Before presenting our model, we briefly present some of the broad productivity patterns in the U.S. sugarbeet manufacturing industry over the 20th century. We'll also contrast these patterns to those in Europe.

As mentioned, a widely available measure of productivity is the recovery rate — the pounds of manufactured-sugar per ton of beets purchased. In Figure 1, we show the U.S. recovery rate over the 20th century. There is a striking relationship between the recovery rate and the regulatory

period: it grew until regulation began, fell throughout the regulatory period, then commenced growing once regulation ceased. And the changes were significant: more than 300 pounds of sugar were recovered from a ton of beets at the beginning of the Sugar Act and less than 250 pounds at the finish. Moreover, the decline in the recovery rate was typically much larger at individual factories (as we'll see below). That is because during the Sugar Act period production shifted toward high recovery rate areas (like California).

In Figure 2, we plot total factor productivity (TFP) for the manufacturing establishments producing beet sugar as calculated by Bartelsman and Gray (1996) (BG) (from the NBER four digit manufacturing industry data). They use a gross-output production function. Beets purchased from farmers is the biggest materials cost for the factories. TFP declined from 1957-1975 by about $15 \%$ 
and then climbed from 1975-1996 by about 20\%. For comparison, we plot TFP for the entire food manufacturing sector (calculated using BG). Food-TFP grew during the period 1957-1975. In the later period, food-TFP grew slower than the sugar-TFP.

Finally, in Figures 3 and 4 we compare the U.S. recovery rate with that in Germany and France, respectively, the two largest European producers. The European recovery rates do not show a decline until 1974 followed by a rebound.

\section{Model}

We begin by constructing a simple model of the industry in the pre-Sugar Act period. Then we will introduce some of the Sugar Acts regulations and explore how these influence performance.

Before the Sugar Act, the price of sugar was equal to the world price plus a tariff. Hence,

for now let's assume that the price of sugar is fixed and given by $p_{y}$. With a fixed price, what determines the size of the industry? Let us briefly talk in general terms, then turn to the specifics of our model. At the farm level, there are fixed costs of entering sugarbeet production (like learning new farming techniques). This limits the number of farms. Farm size (acres in sugarbeets) is limited by the endowment of farmer time. At the factory level, there are obvious fixed costs of building factories. Factory size is limited by transportation costs of beets. Finally, what determines the size of the industry in a region? One factor is soil quality, so that as a region expands, poorer and poorer soil must be used. Though true to some extent, perhaps the most important factor limiting regional production was the cost of acquiring farm-help. Growing beets requires lots of labor, and "regions" found it hard to supply labor.

Regulation influenced the size and operation of all three production units, the farm, the factory and the region. We have models that explore its impact on all three. We have models with transportation costs, and models with increasing costs of expanding regional farm-help. But for clarity, in this paper the only factor limiting size will be fixed time endowments of farmers. More 
precisely, there will be a set of farmers (who have paid fixed costs). Farmers are identical, and we study a representative one. There will be a constant returns to scale factory that processes beets.

\section{A. Technology - Farming}

Consider a representative farmer. We'll assume for simplicity that there are only three farm inputs, $N, M$, and $L$, which are farmer time spent growing beets, the materials used growing beets, and the units of land or acres devoted to beets. Materials are primarily irrigation and fertilizers. These inputs produce sugarbeets that weigh $T$ tons, and have $S$ tons of sugar-in-the-crop. We assume that the technology

$$
S=S(N, M, L)
$$

is differentiable, concave and homogenous of degree one in $(N, M, L)$, and that

$$
T=T(N, M, L)
$$

is also differentiable, concave and homogenous of degree one in $(N, M, L)$.

Quality, or sugar content, $S / T$, of the beets is assumed to only depend on $M / L$ and to be decreasing in this ratio. That is,

$$
q=\frac{S(N, M, L)}{T(N, M, L)}=q\left(\frac{M}{L}\right)
$$

and $q^{\prime}(M / L)<0$. This technology says that an increase in the amount of water (or fertilizer) per acre leads to lower sugar content in the beets. So, holding $N / L$ fixed, irrigation expands sugar-inthe-crop per acre $S / L$, but not as fast as tons per acre, $T / L$.

Why this negative relationship? In fact, at very low levels of irrigation, or fertilizer use, sugar content may increase in $M / L$. But after this initial range, more water or fertilizer increases $S$ but decreases $q$. There is a lot of evidence that the industry operated in this "region." So, this functional form assumption is to keep the algebra simple. 
Regarding the evidence that the industry operated in the region where increases in $M / L$ led to increases in $S$ but decreases $q$, examination of company archives finds many documents of company field representatives complaining that farmers were pursuing growing practices — intensive irrigation and fertilization - that led to lower beet quality but higher $S$ per acre. In fact, some contracts explicitly stated that irrigation and fertilization should not take place after some date. But, of course, these provisions were hard to enforce. We will provide references to these documents later. For now, let's quote from a USDA study shortly after the Sugar Act began, which stated that

“...there are certain cultural practices which have a consistently adverse effect upon the quality of the beet. For example, excessive manuring, which creates a rank top growth, frequently leads to delayed maturity and relatively low sugar content, but high tonnage per acre. Late irrigation has a similar effect as does harvesting at an unusually early date while close spacing is said to have to opposite effect." (p. 27) ${ }^{5}$

\section{B. Technology - Factory}

We assume that the factory technology is

$$
Y=Y(E, T, q)=F(E, T) q
$$

where $F(E, T)$ is differentiable, concave and homogenous of degree one in $(E, T)$, where $E$ is factory energy input. We have one factory input for notional simplicity, and we could easily also include capital and labor. We can write

$$
Y=F(E, T) q=\frac{F(E, T)}{T} q T=f(E / T) S
$$

where $f(E / T)$ is the percentage of sugar, $Y / S$, extracted from the beets. This is typically called the extraction rate. The greater is the factory energy input per ton of beets, the greater is the

\footnotetext{
${ }^{5}$ Charles M. Nicholson, 1939: "Preliminary Report with Respect to Processor-Grower Relations in the U.S. Sugar Beet Industry," USDA Sugar Division report Misc-1.
} 
extraction rate. Since the extraction rate can be no greater than one, we need that $f(E / T)$ satisfies $f(E / T)<1$.

\section{Solving Integrated Problem}

We next turn to analyzing what inputs and output would be chosen given a fixed sugar price. Again, there is a representative farmer that faces no transport costs to a factory that has constant returns to scale. Typically in this industry the farms and factory were not jointly owned. Rather, the factories purchased beets from farmers on the basis of contracts signed before the growing season. In other versions of the paper we analyze the case where these contracts are used. Here, again to simplify, we will study the integrated farm-factory problem. It will be easier, and the qualitative results we find hold in the market case as well.

Before we specify the integrated maximization problem, we discuss input prices. We assume that farmers can purchase land and materials at fixed prices, $P_{L}$ and $P_{M}$. Regrading the value of farmers' time, farmers have a fixed time endowment. Hence, the more time $N$ that a farmer devotes to beets, the greater the opportunity cost of lost time elsewhere. Hence, we assume that the imputed time cost of the farmer, denoted $P_{N}(N)$, is increasing and convex, that is, we assume $P_{N}^{\prime}(N)>0$ and $P_{N}^{\prime \prime}(N)>0$.

The integrated farm-factory problem is

$$
\begin{array}{rl}
\max _{E, L, M, N} & V\left(P_{Y}\right)=P_{y} f\left(\frac{E}{T}\right) S-P_{M} M-P_{L} L-P_{N}(N)-P_{E} E \\
\text { s.t. } & S=S(N, M, L) \text { and } T=T(N, M, L)
\end{array}
$$

where $V\left(P_{Y}\right)$ is the maximized value. The first order necessary conditions (FONCs) are:

$$
L \quad: \quad P_{y}\left[\frac{\partial f\left(\frac{E}{T}\right)}{\partial L} S+\frac{\partial S}{\partial L} f\left(\frac{E}{T}\right)\right]=P_{L}
$$




$$
\begin{aligned}
& M \quad: \quad P_{y}\left[\frac{\partial f\left(\frac{E}{T}\right)}{\partial M} S+\frac{\partial S}{\partial M} f\left(\frac{E}{T}\right)\right]=P_{M} \\
& N \quad: \quad P_{y}\left[\frac{\partial f\left(\frac{E}{T}\right)}{\partial N} S+\frac{\partial S}{\partial N} f\left(\frac{E}{T}\right)\right]=P_{N}^{\prime}(N) \\
& E \quad: \quad P_{y} \frac{\partial f\left(\frac{E}{T}\right)}{\partial E} S=P_{E}
\end{aligned}
$$

Let's suppose for the moment that these conditions are also sufficient (see below). Let's solve for $\frac{E}{T}, \frac{M}{L}, \frac{N}{L}$ and $N$. Considering the first equation, the term $\frac{\partial f\left(\frac{E}{T}\right)}{\partial L} S$ is loss in output $Y$ because the extraction rate falls (as tons $T$ expand with $E$ fixed). We can write the term as:

$$
\frac{\partial f\left(\frac{E}{T}\right)}{\partial L} S=\frac{Y / L}{Y / L} \frac{\partial f\left(\frac{E}{T}\right)}{\partial L} S=-\frac{Y}{L} \varepsilon_{T, L} \varepsilon_{f}
$$

where $\varepsilon_{T, L}=\frac{\partial T}{\partial L} \frac{L}{T}$ and $\varepsilon_{f}=\frac{f^{\prime}(x)}{f(x)} x$, since

$$
\frac{\partial f\left(\frac{E}{T}\right)}{\partial L}=f^{\prime}\left(\frac{E}{T}\right)\left(\frac{-E}{T}\right) \frac{\partial T}{\partial L} \frac{1}{T} .
$$

The term $\frac{\partial S}{\partial L} f\left(\frac{E}{T}\right)$ is gain in output $Y$ because sugar-in-the-crop $S$ expands. We can write term as:

$$
\frac{\partial S}{\partial L} f\left(\frac{E}{T}\right)=\frac{Y / L}{Y / L} \frac{\partial S}{\partial L} f\left(\frac{E}{T}\right)=\frac{Y}{L} \varepsilon_{S, L}
$$

where $\varepsilon_{S, L}=\frac{\partial S}{\partial L} \frac{L}{S}$. Therefore, we can write the first two FONCs as:

$$
\begin{aligned}
L & : \quad P_{y} \frac{Y}{L}\left[\varepsilon_{S, L}-\varepsilon_{T, L} \varepsilon_{f}\right]=P_{L} \\
M & : \quad P_{y} \frac{Y}{M}\left[\varepsilon_{S, M}-\varepsilon_{T, M} \varepsilon_{f}\right]=P_{M}
\end{aligned}
$$

Suppose that the elasticities above are constant. Clearly, we need

$$
\text { Assumption: } \varepsilon_{S, L}>\varepsilon_{T, L} \varepsilon_{f} \text { and } \varepsilon_{S, M}>\varepsilon_{T, M} \varepsilon_{f} \text {, }
$$

Then, we can write

$$
\frac{M}{L}=\frac{\varepsilon_{S, M}-\varepsilon_{T, M} \varepsilon_{f}}{\varepsilon_{S, L}-\varepsilon_{T, L} \varepsilon_{f}} \frac{P_{L}}{P_{M}}
$$


Hence, $M / L$ does not depend on $P_{Y}$. We can write the fourth FONC as:

$$
P_{y} f^{\prime}\left(\frac{E}{T}\right) q\left(\frac{M}{L}\right)=P_{E}
$$

Hence, given $M / L$, we can solve for $E / T$. Let us summarize this as

Proposition 1. Increases in the price do not change quality, and increase the extraction rate.

Hence, the recovery rate increases.

The lesson from this is that as industry price increases, recovery rates increase — just the opposite of what happened during the regulation period.

\section{Regulation: Fair-Division Provisions Reduces Productivity}

There were two features of regulation: reduced competition and the fair-division provisions. Reducing competition led, among other things, to higher prices (than if there was no reduction in competition). The value to producers of higher prices can be calculated using $V\left(P_{Y}\right)$. Our focus will be on the fair-division provisions, and showing that they reduced productivity (this section), and because of this, reduced surplus, that is, for any $P_{Y}$, that $V\left(P_{Y}\right)<V_{R}\left(P_{Y}, \tau, \sigma\right)$, where $V_{R}\left(P_{Y}, \tau, \sigma\right)$ is total producer surplus under the fair-division provisions.

The fair-division provisions called for subsidizing production of $S$ and taxing production of $Y$. We study how this policy influences an integrated farm/factory. Assume the price of sugar, $p_{Y}$, is fixed. ${ }^{6}$ Revenue before regulation was $p_{Y} Y$. Now revenue is $(1-\tau) p_{Y} Y+\sigma p_{Y} S$, where $\tau$ and $\sigma$ are the tax and subsidy rates. The new problem is just like the old except that the previous revenue, $P_{y} f(E / T) S$, is replaced with

$$
(1-\tau) P_{y} f\left(\frac{E}{T}\right) S+\sigma P_{y} S
$$

where $\tau$ and $\sigma$ are the tax and subsidy rates, and are taken as given.

\footnotetext{
${ }^{6}$ While the government did not literally set the price of sugar, given it gave quotas to foreign and domestic producers, it had substantial control of price.
} 
The new integrated farm-factory problem is

$$
\begin{aligned}
& \max _{E, L, M, N} \quad V_{R}\left(P_{Y}, \tau, \sigma\right)=(1-\tau) P_{y} f\left(\frac{E}{T}\right) S+\sigma P_{y} S-P_{M} M-P_{L} L-P_{N}(N)-P_{E} E \\
& \text { s.t. } \quad S=S(N, M, L) \text { and } T=T(N, M, L)
\end{aligned}
$$

where $V_{R}\left(P_{Y}, \tau, \sigma\right)$ is the maximized value under the fair-division provisions.

The FONCs are as in the previous case except that $(1-\tau) P_{y}$ replaces $P_{y}$, and there is an extra term in the bracket of the first three first order conditions, namely $\sigma \frac{\partial S}{\partial L}$ in the first, and so on. We can write $\sigma \frac{\partial S}{\partial L}$ as

$$
\frac{Y / L}{Y / L} \sigma \frac{\partial S}{\partial L}=\frac{Y}{L}\left[\sigma \frac{\partial S}{\partial L} \frac{L}{Y}\right]=\frac{Y}{L}\left[\sigma \frac{\partial S}{\partial L} \frac{L}{S} \frac{1}{f(\cdot)}\right]=\frac{Y}{L}\left[\sigma \varepsilon_{S, L} \frac{1}{f(\cdot)}\right]
$$

So equation (2) now becomes

$$
\frac{M}{L}=\frac{\varepsilon_{S, M}+\sigma \varepsilon_{S, M} \frac{1}{f(\cdot)}-\varepsilon_{T, M} \varepsilon_{f}}{\varepsilon_{S, L}+\sigma \varepsilon_{S, L} \frac{1}{f(\cdot)}-\varepsilon_{T, L} \varepsilon_{f}} \frac{P_{L}}{P_{M}} .
$$

We want to show irrigation per acre increases, or

$$
\frac{\varepsilon_{S, M}+\sigma \varepsilon_{S, M} \frac{1}{f(\cdot)}-\varepsilon_{T, M} \varepsilon_{f}}{\varepsilon_{S, L}+\sigma \varepsilon_{S, L} \frac{1}{f(\cdot)}-\varepsilon_{T, L} \varepsilon_{f}}>\frac{\varepsilon_{S, M}-\varepsilon_{T, M} \varepsilon_{f}}{\varepsilon_{S, L}-\varepsilon_{T, L} \varepsilon_{f}}
$$

Let $A=\varepsilon_{S, M}-\varepsilon_{T, M} \varepsilon_{f}$ and $B=\varepsilon_{S, L}-\varepsilon_{T, L} \varepsilon_{f}$. Then we want to show

$$
A B+B \sigma \varepsilon_{S, M} f^{-1}>A B+A \sigma \varepsilon_{S, L} f^{-1}
$$

or $B \varepsilon_{S, M}>A \varepsilon_{S, L}$, or $\varepsilon_{T, M} \varepsilon_{S, L}>\varepsilon_{S, M} \varepsilon_{T, L}$. Because $q(M / L)$ is decreasing, $\varepsilon_{T, M}>\varepsilon_{S, M}$ and $\varepsilon_{S, L}>\varepsilon_{T, L} \cdot{ }^{7}$ Hence, we have

Proposition 2. The fair-division provisions (that is, $\tau>0$ and $\sigma>0$ ) lead to increases in $M / L$, and decreases in quality $q()$.

\footnotetext{
${ }^{7}$ Recall that $q=q(M / L)$ is decreasing, so that $\partial q / \partial L>0$. Since $q=S(N, M, L) / T(N, M, L)$, we have that $\frac{\partial q}{\partial L}=\frac{1}{T^{2}}\left[\frac{\partial S}{\partial L} T-\frac{\partial T}{\partial L} S\right]=\frac{S}{T}\left[\frac{\partial S}{\partial L} \frac{1}{S}-\frac{\partial T}{\partial L} \frac{1}{T}\right]=\frac{S}{T} \frac{1}{L}\left[\frac{\partial S}{\partial L} \frac{L}{S}-\frac{\partial T}{\partial L} \frac{L}{T}\right]$ so that $\varepsilon_{S, L}>\varepsilon_{T, L}$. A similar calculation shows that $\varepsilon_{T, M}>\varepsilon_{S, M}$.
} 
The intuition is clear: when we farmed before the subsidy, we were worried about how easily the sugar in the beets could be extracted. Now, we are less worried about extraction because we get paid for the sugar-in-the-crop as well.

Now, equation (3) becomes

$$
(1-\tau) P_{y} f^{\prime}\left(\frac{E}{T}\right) q\left(\frac{M}{L}\right)=P_{E}
$$

We have already seen (Proposition 2) that the fair-division provisions reduce quality. Hence, this means $E / T$ falls so that the extraction rate falls. But there is another effect: since $\tau>0$, there is a direct force reducing $E / T$ and the extraction rate. Hence, we have

Proposition 3. The fair-division provisions (that is, $\tau>0$ and $\sigma>0$ ) reduce $E / T$ and the extraction rate $f(E / T)$ through an indirect channel (since $q$ falls) and a direct channel through taxes on final output.

In summary, the fair-division provisions lead to reductions in the recovery rate since quality falls and the extraction rate falls.

Before finishing this section, a few words about the maximization problems above. We have studied the response to regulations in a static model. At the beginning of the Sugar Act period, the subsidy from the government to farmers amounted to about $50 \%$ of the amount farmers received from factories. ${ }^{8}$ This was obviously a huge payment and meant that farmers were now considering wholesale changes in how they farmed sugarbeets. It would obviously take farmers time to adjust to the new economic environment, to figure out new farming methods to best profit from it. Hence, we should expect that the response to the tax/subsidy scheme was drawn out through time.

To capture this, we could take the static maximization problem above and add a human capital variable to the $S(\cdot)$ function. So, as farmers started to increase irrigation intensity, quality would fall, and the increase in $S$ per acre would quit after some time. But through learning, the farmers could figure out how to push off this point at which increases in $S$ quit.

\footnotetext{
${ }^{8}$ The amount of the subsidy was reduced to about 25 percent of the factory payment after WWII.
} 
As we'll see in the individual factory data below, the fall in recovery rates was drawn out for a long time, and continued throughout the Sugar Act period. This was not only due to farmers learning how to irrigate and fertilize intensively. There were also innovations in general farming which enabled farmers to push quality lower yet keep increasing $S$. One of these innovations was the improvement in fertilizers. There is research showing that during the 1950s, the government attempted to control output in other crops through acreage restrictions yet had little success. The research shows that increases in fertilizer use per acre was responsible (see Christensen and Aines (1962)).

This learning about new farming techniques to best profit from the tax/subsidy scheme of the Sugar Act is evident in the non-irrigated farming areas. In the technology $q(M / L)$ above, we let $M / L$ denote irrigation or fertilizer use per unit land. In fact, in 1934 farmers knew how to manipulate $S(N, M, L)$ by varying irrigation per unit land but had little knowledge how to do this by varying fertilizer use per unit land. So, in non-irrigated areas, farmers could do little to expand sugar-in-the-crop per unit land at the start of the Sugar Act. But there is much evidence to show they did learn to use fertilizer to achieve (to some extent) what farmers in irrigated areas could do with water. But this took time, and it was not until the late 1940s that one sees recovery rates falling in non-irrigated areas to the extent they did in irrigated areas at the start of the Sugar Act.

As the Sugar Act ended, and the subsidy/tax scheme abandoned, then the converse was true. Farmers had to figure out the best way to farm under the new regime where there was no subsidy. So, we should expect to see that increases in recovery rates are drawn out over time.

Let us now turn to look further at recovery rates by companies and factories.

\section{Company and Factory Productivity Statistics}

In this section we present productivity statistics at the company and factory levels. 


\section{A. Company Recovery Rate}

There were seven major sugarbeet companies at the start of the Sugar Act: Amalgamated, American Crystal, Great Western Sugar, Holly Sugar, Michigan Sugar, Utah\&Idaho Sugar, and Spreckels. Together these companies produced the vast majority of U.S. beet-sugar output. In Figures 5A-5B, we display the recovery rates for each of these companies. American Crystal had the widest geographic distribution of factories and we break the company into two parts - factories in the west and those in the Red River Valley.

The recovery rates of the four companies in Figure 5A, American Crystal (west), Spreckels, Utah \& Idaho Sugar, and Amalgamated Sugar all share a similar pattern as the U.S. average: a rising (or steady) recovery rate until 1934, then a fairly quick and steady decline, and an increase afterwards.

A few remarks on the companies in Figure 5A. American Crystal (AC) is still in operation today - a thriving company, in fact. AC closed its western factories in the mid to late 1970's and its factories today are primarily in the Red River Valley (see Figure 5B). For Spreckel's Sugar, we only have one factory - Factory \#1. It was a huge factory - many times bigger than any other U.S. factory. It was closed in 1982. Utah \& Idaho was a Mormon affiliated company. It was closed in the late 1970's. Amalgamated Sugar is still an ongoing company.

Figure 5B shows the recovery rate for the other four companies. The patterns here are also similar to the U.S. national average. One difference between Figure 5A and the bottom two panels in Figure 5B is that the recovery rates for AC (Red River Valley) and Michigan Sugar Company do not start a sustained downward fall until the early 1950's. The reason is that the factories in these two companies are in the Midwest, where there is no irrigation. For the other six companies, factories were located in irrigated farming areas. As mentioned, it took time for farmers to learn fertilizing techniques that mimicked irrigation.

A few remarks on the companies in Figure 5B. The Great Western was the largest producer 
at the start of the Sugar Act. For Holly Sugar, we only have one factory - Sydney, Montana. Michigan Sugar is still an operating concern (note we have the recovery rate for 2002 in Figure 5B).

\section{B. Factory Recovery Rates}

In Figures 6A-6C we present the recovery rates for American Crystal's major factories. One can see that the recovery rates of the four factories in Figure $6 \mathrm{~A}$ fall very rapidly soon after the Sugar Act is enacted. These factories are all in areas with irrigated farms. The drops in recovery rates in California are truly amazing. A word about the Rocky Ford Factory. Before the Sugar Act, bad weather made its recovery rate very volatile. We have fitted a cubic polynomial to the recovery rates. In future versions we may add simple controls for the weather.

The next eight factories, in Figures 6B-6C, are in non-irrigated areas. The four factories in Figure $6 \mathrm{~B}$ all show declining recovery rates during the Sugar Act. Their patterns differ from the factories in Figure 6A in that the rates didn't begin to fall until after WWII. The four factories in Figure $6 \mathrm{C}$ all show similar patterns to the national average except for the Chaska factory. As we said, the pattern holds in nearly all factories, but there are a few exceptions.

\section{Other Productivity Measures}

Until this point, we have primarily used recovery rates as our measure of productivity or performance. For many factory/farm operations, we have data on factory labor input (hours), factory energy used (BTUs consumed) and factory capital usage (days operated). These data are more plentiful in the period before WWII. For the farms, we have acres. For these factories, labor productivity $\left(Y / N_{\text {fact }}\right.$, where $N_{\text {fact }}$ equals hours worked) and energy productivity $(Y / E$, where $E$ equals BTUs) follow the same patterns as the factory recovery rates: they increase until 1934, then fall until WWII (where our data on labor input ends for most of these factories). Note that this means labor productivity and energy productivity continued to grow throughout the Great Depression. It was not until the Sugar Act of 1934 that they started to decline. 
We have not as yet attempted to construct measures of TFP for individual farm/factory units. Our (partial) factory productivity measures (like $Y / N_{\text {fact }}$ and $Y / E$ ) show trend reversal, from positive to negative growth. Our (partial) farm productivity measures (like $Y / L$ ) show a slowdown in trend. Hence, we are fairly confident that standard measures of TFP growth would show a significant decline at the start of the Sugar Act in 1934. But it's not clear that TFP growth remained negative throughout the Sugar Act period at individual factories.

\section{Regulation: Fair-Division Provisions Reduce Producer Surplus}

We next examine the impact of fair-division provisions on economic surplus. We'll prove it destroys surplus (Proposition 4 below), and then present a preliminary quantitative exploration.

To show a surplus loss, we want to compare $V_{R}\left(P_{Y}, \tau, \sigma\right)$ in problem (4) with $V\left(P_{Y}\right)$ in problem (1). During the first years of the Sugar Act, subsidies equaled taxes. Hence, we'll start by comparing $V_{R}\left(P_{Y}, \tau, \sigma\right)$ with $V\left(P_{Y}\right)$ under a balanced budget condition. In particular, we examine pairs $(\tau, \sigma)$ such that, given $\sigma, \tau$ is chosen to satisfy

$$
\tau P_{Y} Y(\tau, \sigma)=\sigma P_{Y} S(\tau, \sigma)
$$

where $Y(\tau, \sigma)$ and $S(\tau, \sigma)$ are the values of sugar-in-the-bag and crop from problem $(4)$. Let $\tau(\sigma)$ denote the solution to the above equation. Of course, a solution may exist only for small $\sigma$. We study the percentage welfare loss from fair-division, that is,

$$
\operatorname{Loss}(\sigma)=1-\frac{V_{R}\left(P_{Y}, \tau(\sigma), \sigma\right)}{V\left(P_{Y}\right)}
$$

and see how it varies with $\sigma$. It's easy to show that there is a loss:

Proposition 4. Subsidizing sugar-in-the-crop, and funding the subsidies with taxes on sugarin-the-bag, reduces producers surplus.

Proof. When the budget is balanced, then $(1-\tau) P_{y} f\left(\frac{E}{T}\right)+\sigma P_{y} S=P_{y} f\left(\frac{E}{T}\right) S$. Hence, the revenue function in the fair-division case is the same as the revenue function without the provisions. The costs are the same in the two cases. Since the choices of inputs in the no fair-division case 
maximize revenue less costs, and the choices in the fair-division case are different, it must be that $V_{R}\left(P_{Y}, \tau, \sigma\right)<V\left(P_{Y}\right)$

We now turn to present a preliminary quantitative exploration of the surplus loss from the fair-division provisions. For the quantitative exercise, we use the following functional forms:

$$
\begin{aligned}
Y & =Y(E, T, q)=A_{Y} E^{\gamma} T^{1-\gamma} q \\
S & =S(N, M, L)=A_{S} N^{\mu} M^{\omega_{S}} L^{\lambda_{S}} \\
T & =T(N, M, L)=A_{T} N^{\mu} M^{\omega_{T}} L^{\lambda_{T}} \\
q & =\frac{S}{T}=q\left(\frac{M}{L}\right)=\frac{A_{S} N^{\mu} M^{\omega_{S}} L^{\lambda_{S}}}{A_{T} N^{\mu} M^{\omega_{T}} L^{\lambda_{T}}}=\frac{A_{S}}{A_{T}}\left(\frac{M^{\omega_{S}-\omega_{T}}}{L^{\lambda_{T}-\lambda_{S}}}\right)=\frac{A_{S}}{A_{T}}\left(\frac{M}{L}\right)^{\omega_{S}-\omega_{T}}
\end{aligned}
$$

where $\gamma \varepsilon(0,1)$ and $\mu+\omega_{i}+\lambda_{i}=1$ for $i=S, T$. We assume that $\omega_{T}>\omega_{S}$, so that $\lambda_{S}>\lambda_{T}$. Also, we assume the opportunity cost of farmer time is $P_{N}(N)=N^{\rho}$, where $\rho>1$. We have proven

Proposition 5. The FONC are also sufficient in both problems for these functional forms.

There are a large number of parameters we must house. There is not a lot of information about these parameters in the economics literature. For now, we have chosen elasticity parameters that we think are reasonable. We have chosen the TFP parameters so that the model matches some key pre Sugar Act statistics, including those for $q$ and the extraction rate. The parameter values used in the calculations below are given in Table 1:

\begin{tabular}{lll} 
Table 1 & & \\
\hline$P_{L}=P_{M}=1$ & $P_{Y}=1.3924$ & $P_{E}=0.10827$ \\
$A_{S}=4.9353$ & $A_{T}=49.155$ & $A_{e}=1$ \\
$\omega_{S}=0.3$ & $\lambda_{S}=0.5$ & \\
$\omega_{T}=0.6$ & $\lambda_{T}=0.2$ & \\
$\rho=2$ & $\mu=0.2$ & $\gamma=0.4$
\end{tabular}


For a given $\sigma$, the balanced budget $\tau$ satisfies

$$
\tau=\sigma \frac{S(\tau, \sigma)}{Y(\tau, \sigma)}
$$

In Diagram 1, a balanced budget $\tau$ will correspond to an intersection of the 45 degree line and the curve $\sigma S(\tau, \sigma) / Y(\tau, \sigma)$ (where there is a curve for each $\sigma$ ). If there are two intersections, we choose the smallest $\sigma$. As $\sigma$ increases, the curve shifts up. We see that an intersection exists only for $\sigma<.26$

In Diagram 2, there are four panels showing how some key statistics vary with the subsidy rate, $\sigma$. The subsidy rate varies between 0 and 10 percent. The upper left panel shows that as the subsidy is introduced, both $Y$ and $S$ increase. At a 10 percent subsidy, $Y$ is 10 percent higher and $S$ is 30 percent higher. Sugar content, extraction, and hence the recovery rate fall throughout.

In Diagram 3, we plot the percentage welfare loss from the fair-division provisions. At a 2.5 percent subsidy, the welfare loss is about 2.5 percent. At a 10 percent subsidy, the welfare loss is over 20 percent. These are very large welfare losses. Our quantitative analysis is still very preliminary, so these numbers may change a lot. But perhaps it should not be surprising that they are big. After all, this was a system where one part of the operation was subsidized to make inputs, while another part was taxed on making output.

\section{Discussion}

In this section, let us briefly summarize our findings and then discuss future work. We have shown that the start of the Sugar Acts corresponded with the beginning of falling productivity in U.S. sugar manufacturing - falling recovery rates and other productivity measures. Once the Sugar Acts ended, these trends reversed. We showed that the fair-division provisions of the Sugar Act would have led (qualitatively) to these productivity movements. We showed that the fair-division provisions reduced producer surplus, and that the losses may have been very big.

In this paper, to keep the exposition simple, we analyzed the impact of regulation studying 
the integrated farm-factory problem. As mentioned, farms and factories were typically not jointly owned. Factories bought beets from farmers based on contracts signed before the growing season. We have studied the impact of Sugar Act regulations in the market case, when contracts are used to buy and sell beets. In the next version of this paper, we'll present these results. The qualitative results above hold in the market case, though we have not explored the quantitative results.

In this paper we have focused on two major distortions caused by the fair-division provisions: a change in the mix of farm inputs (more intensive fertilization per acre) and a change in the scale of the factory relative to the farm. In fact, the Sugar Act regulations led to other major production distortions. It distorted the regional distribution of production and it distorted average farm size. During the period of the Sugar Acts, the fraction of sugarbeet acres in the Far West grew. Once the Sugar Acts ended, the Far West rapidly began to decline, and the Midwest's share of acres has expanded dramatically. Regarding average farm size, once the Sugar Act ended, average farm size declined in some Western states while it grew rapidly in Minnesota and North Dakota. In future versions we'll show how the Sugar Acts distorted location and average farm size decisions.

We are also studying the impact of the Sugar Act regulations in the cane-sugar manufacturing industry. We have decided to put that analysis in a separate paper.

Finally, we have not spent much time discussing how lack of competition influenced productivity in the beet-sugar manufacturing industry. That will wait for another paper. 


\section{References}

[1] Acemoglu, Daron, and Amy Finkelstein (2006): "Input and Technology Choices in Regulated Industries: Evidence from the Health Care Sector," MIT, mimeo.

[2] Bartelsman, Eric, and Wayne Gray (1996): "The NBER Manufacturing Productivity Database," NBER Technical Working Paper 205, October.

[3] Beghin, John, Barbara El Osta, Jay R. Cherlow, and Samarendu Mohanty (2003): "The Cost of the U.S. Sugar Program Revisited," Contemporary Economic Policy 21, No. 1 (January): $106-16$.

[4] Boyer, Kenneth D. (1987): "The Costs of Price Regulation: Lessons from Railroad Deregulation," RAND Journal of Economics 18, No. 3 (Autumn): 408-416.

[5] Card, David (1998): Deregulation and labor earnings in the airline industry. In Regulatory Reform and Labor Markets, edited by J. Peoples. Norwell, MA: Kluwer Academic Publishing, $183-230$.

[6] Christensen, Raymond P., and Ronald O. Aines (1962): "Economic effects of acreage control programs in the 1950s," (October), USDA Agricultural Economic Report 18.

[7] Cole, Harold L., and Lee E. Ohanian (2004): "New Deal Policies and the Persistence of the Great Depression: A General Equilibrium Analysis," Journal of Political Economy 112, No. 4 (August): 779-816.

[8] Cottrell, R. H. (Editor) (1952): Beet Sugar Economics. Caldwell, ID: Caxton Printers.

[9] Crawford, Gregory (2000): "The Impact of the 1992 Cable Act on Household Demand and Welfare," RAND Journal of Economics 31, No. 3 (Autumn): 422-449. 
[10] Dye, Alan (1994): "Avoiding Holdup: Asset Specificity and Technical Change in the Cuban Sugar Industry, 1899-1929," Journal of Economic History 54, No. 3 (September): 628-653.

[11] Ellison, Sara Fisher, and Wallace P. Mullin (1995): "Economics and Politics: The Case of Sugar Tariff Reform," Journal of Law and Economics 38, No. 2 (October): 335-66.

[12] Galdon-Sanchez, Jose E., and James A. Schmitz, Jr. (2002): "Competitive Pressure and Labor Productivity: World Iron-Ore Markets in the 1980s," American Economic Review 92, No. 4 (September): 1222-1235.

[13] Gale, Johnson, D. (1974): The Sugar Program: Large Costs and Small Benefits. Washington, DC: American Enterprise Institute for Public Policy Research.

[14] Genesove David, and Wallace Mullin (2001): "Rules, Communication, and Collusion: Narrative Evidence from the Sugar Institute Case," American Economic Review 91, No. 3 (June): 379398.

[15] Goolsbee, Austan, and Amil Petrin (2004): "The Consumer Gains from Direct Broadcast Satellites and the Competition with Cable TV," Econometrica 72, No. 2 (March): 351-381.

[16] Gwo-Jiun M. Leu, Andrew Schmitz, and Ronald D. Knutson (1987): "Gains and Losses of Sugar Program Policy Options," American Journal of Agricultural Economics 69, No. 3 (August): 591-602.

[17] Heston, Thomas (1987): Sweet Subsidy: The Economic and Diplomatic Effects of the U.S. Sugar Acts 1934-74. New York: Garland Publishing.

[18] Hoffman, Elizabeth, and Gary Libecap (1995): "The Failure of Government-Sponsored Cartels and Development of Federal Farm Policy," Economic Inquiry 33, No. 3 (July): 365-82. 
[19] Holmes, Thomas, and James A. Schmitz, Jr. (2001): "Competition at Work: Railroads vs. Monopoly in the U.S. Shipping Industry," Federal Reserve Bank of Minneapolis Quarterly Review 25, No. 2 (Spring): 3-29.

[20] Hsieh, Chang-Tai, and Peter Klenow, "Misallocation and Manufacturing TFP in China and India," Stanford, mimeo.

[21] Knittel, Christopher R. (2004): "Regulatory Restructuring and Incumbent Price Dynamics: The Case of U.S. Local Telephone Markets," Review of Economics and Statistics 86, No. 2 (May): 614-625.

[22] Koenig, Jeanine (1996): Vertical Integration and Contracts: Application to the U.S. Beet Sugar Industry. Ph.D. dissertation, Washington University, St. Louis.

[23] MacDonald, James M., and Linda C. Cavalluzzo (1996): "Railroad Deregulation: Pricing Reforms, Shipper Responses, and the Effects on Labor," Industrial and Labor Relations Review 50, No. 1 (October): 80-91.

[24] Markiewicz, Kira, Nancy L. Rose, and Catherine Wolfram (2007): "Does Competition Reduce Costs? Assessing the Impact of Regulatory Restructuring on U.S. Electric Generation Efficiency," MIT Department of Economics Working Paper No. 04-37.

[25] Olley, G. Steven, and Ariel Pakes (1996): "The Dynamics of Productivity in the Telecommunications Equipment Industry," Econometrica 64, No. 6 (November): 1263-1297.

[26] Prescott, Edward (1998): "Needed: A Theory of TFP," International Economic Review 39, No. 3 (August): 525-551.

[27] Restuccia, Diego, and Richard Rogerson (2004): "Policy Distortions and Aggregate Productivity with Heterogeneous Plants," 2004 Meeting Papers 69, Society for Economic Dynamics. 
[28] Rose, Nancy L. (1987): "Labor Rent Sharing and Regulation: Evidence from the Trucking Industry," Journal of Political Economy 95, No. 6 (December): 1146-1178.

[29] Ryan, Stephan, "The Costs of Environmental Regulation in a Concentrated Industry," NBER Working Paper 9726, National Bureau of Economic Research.

[30] Schmitz, James (2005): "What Determines Productivity? Lessons from the Dramatic Recovery of the U.S. and Canadian Iron Ore Industries Following Their Early 1980s Crisis," Journal of Political Economy 113, No. 3 (June): 582-625.

[31] Shoptaugh, Terry (1997): Roots of Success: History of the Red River Valley Sugarbeet Growers. Institute for Regional Studies. North Dakota State University.

[32] Stigler, George (1971): "The Theory of Economic Regulation," Bell Journal of Economics 2, No. 1 (Spring): 3-21.

[33] Syverson, Chad (2003): "Market Structure and Productivity: A Concrete Example," University of Chicago Working Paper.

[34] United States Department of Agriculture (1939): "Preliminary Report With Respect to Processor-Grower Relations in the U.S. Sugar Beet Industry," Sugar Division.

[35] Ying, John S., and Theodore E. Keeler (1991): "Pricing in a Deregulated Environment: The Motor Carrier Experience," RAND Journal of Economics 22, No. 2 (Summer): 264-273. 
Figure 1

Pounds of Manufactured-Sugar Per Ton of Purchased Beets

(Recovery Rate)

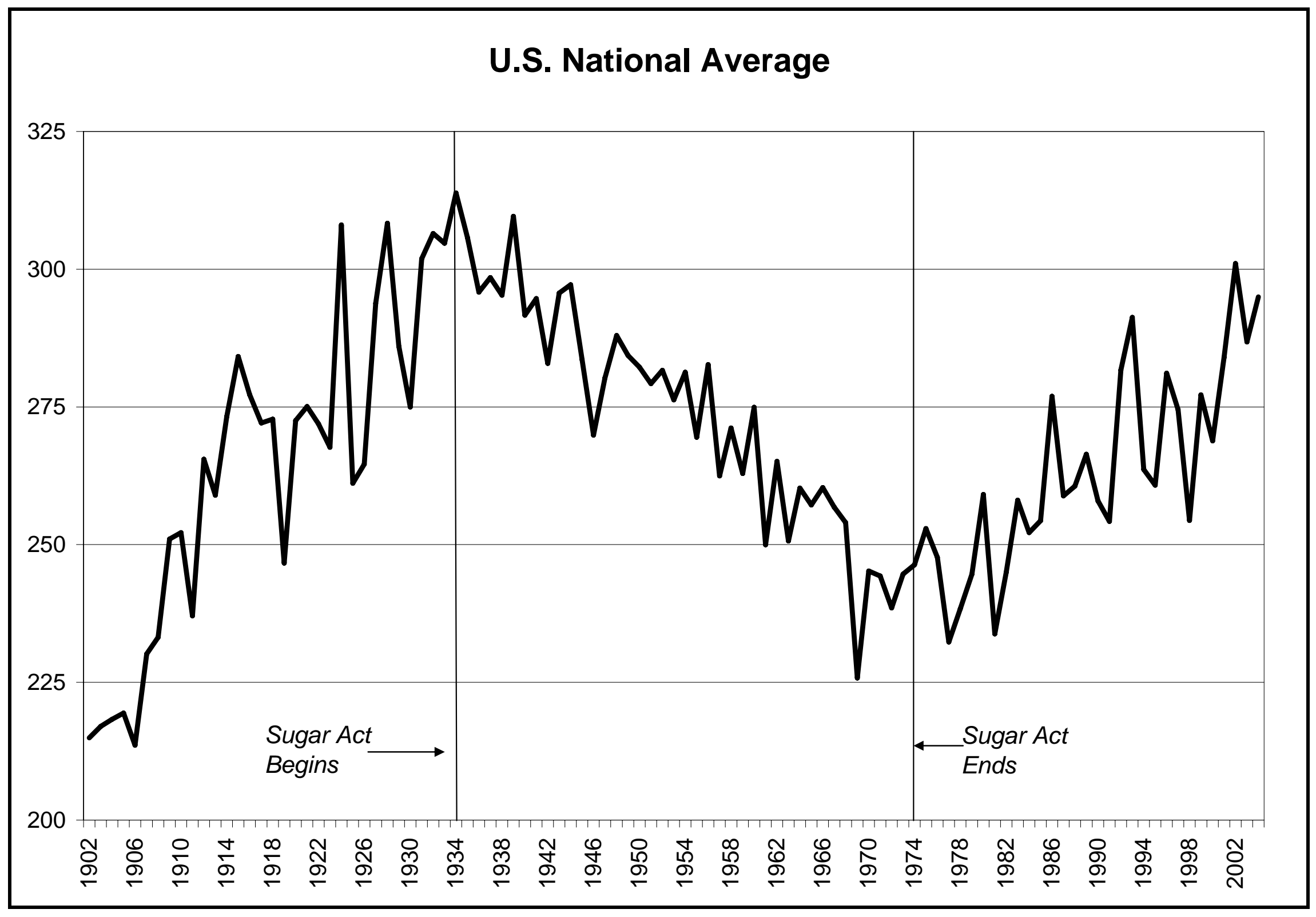


Figure 2

Total Factor Productivity (TFP)

U.S. Sugarbeet Manufacturing and U.S. Food Manufacturing

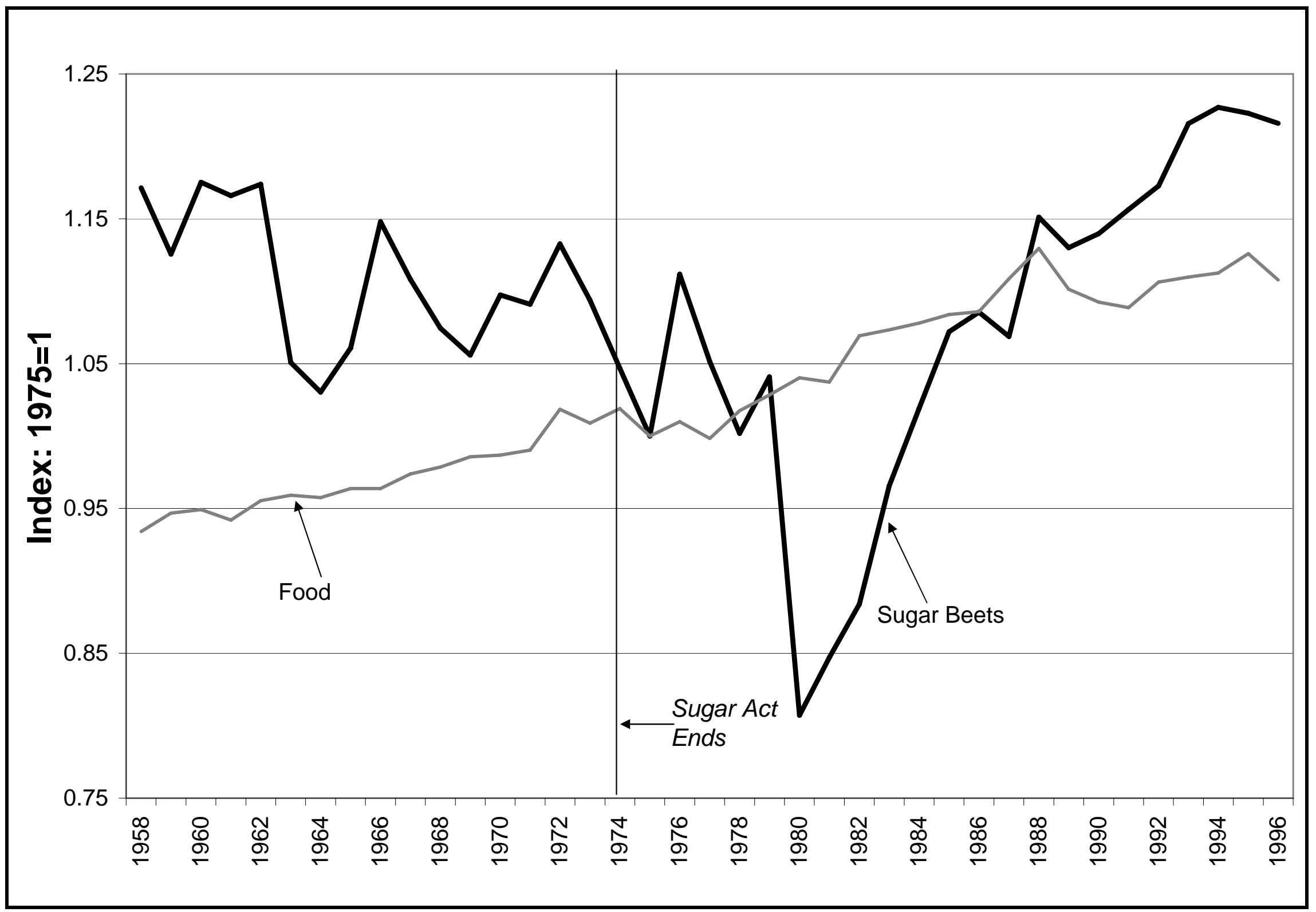


Figure 3

Pounds of Manufactured-Sugar Per Ton of Purchased Beets

(Recovery Rate)

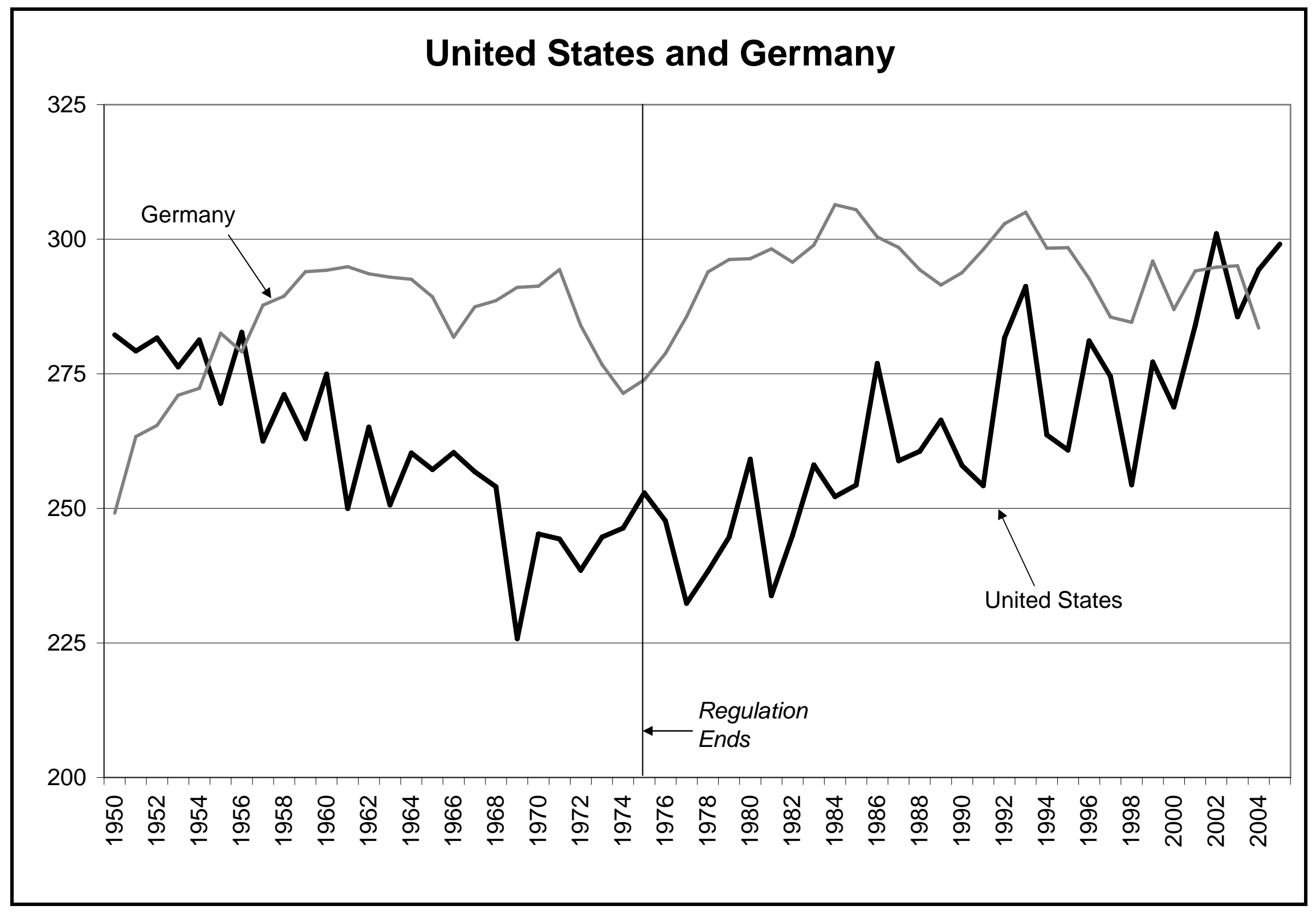


Figure 4

Pounds of Manufactured-Sugar Per Ton of Purchased Beets

(Recovery Rate)

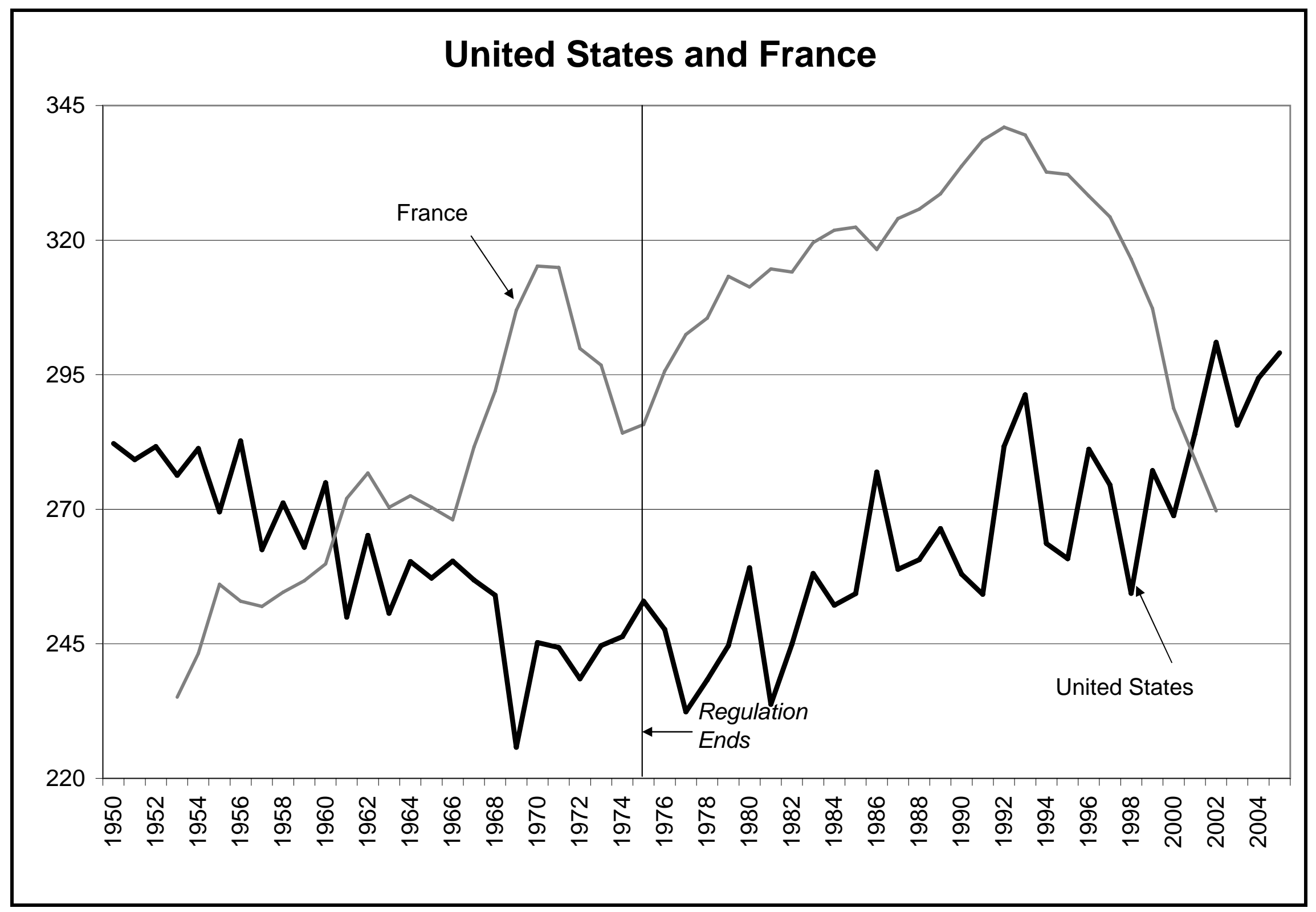


Figure 5A

Pounds of Manufactured-Sugar Per Ton of Purchased Beets

(Recovery Rate)

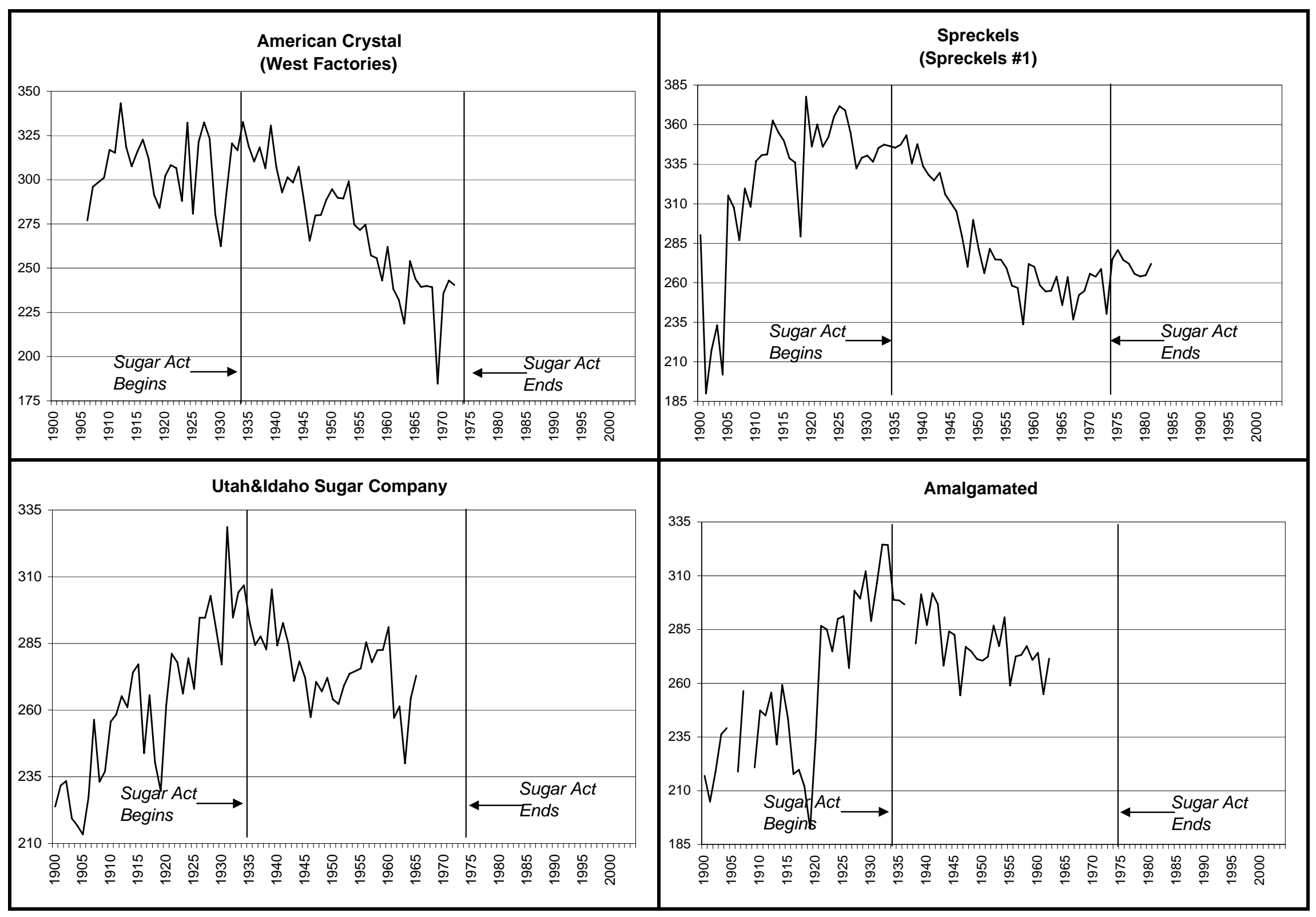


Figure 5B

Pounds of Manufactured-Sugar Per Ton of Purchased Beets

(Recovery Rate)

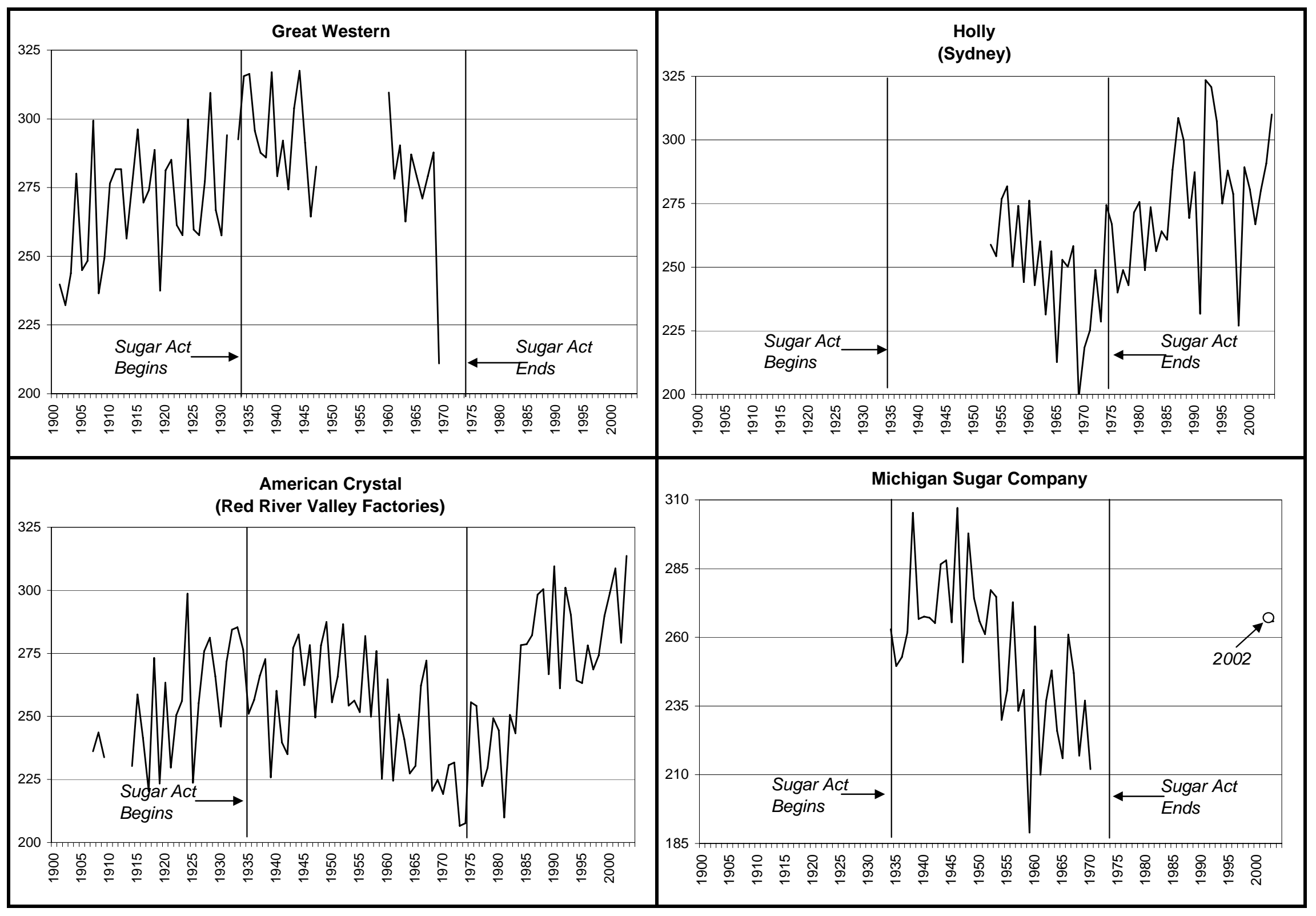


Figure 6A

Pounds of Manufactured-Sugar Per Ton of Purchased Beets

(Recovery Rate)

American Crystal Factories

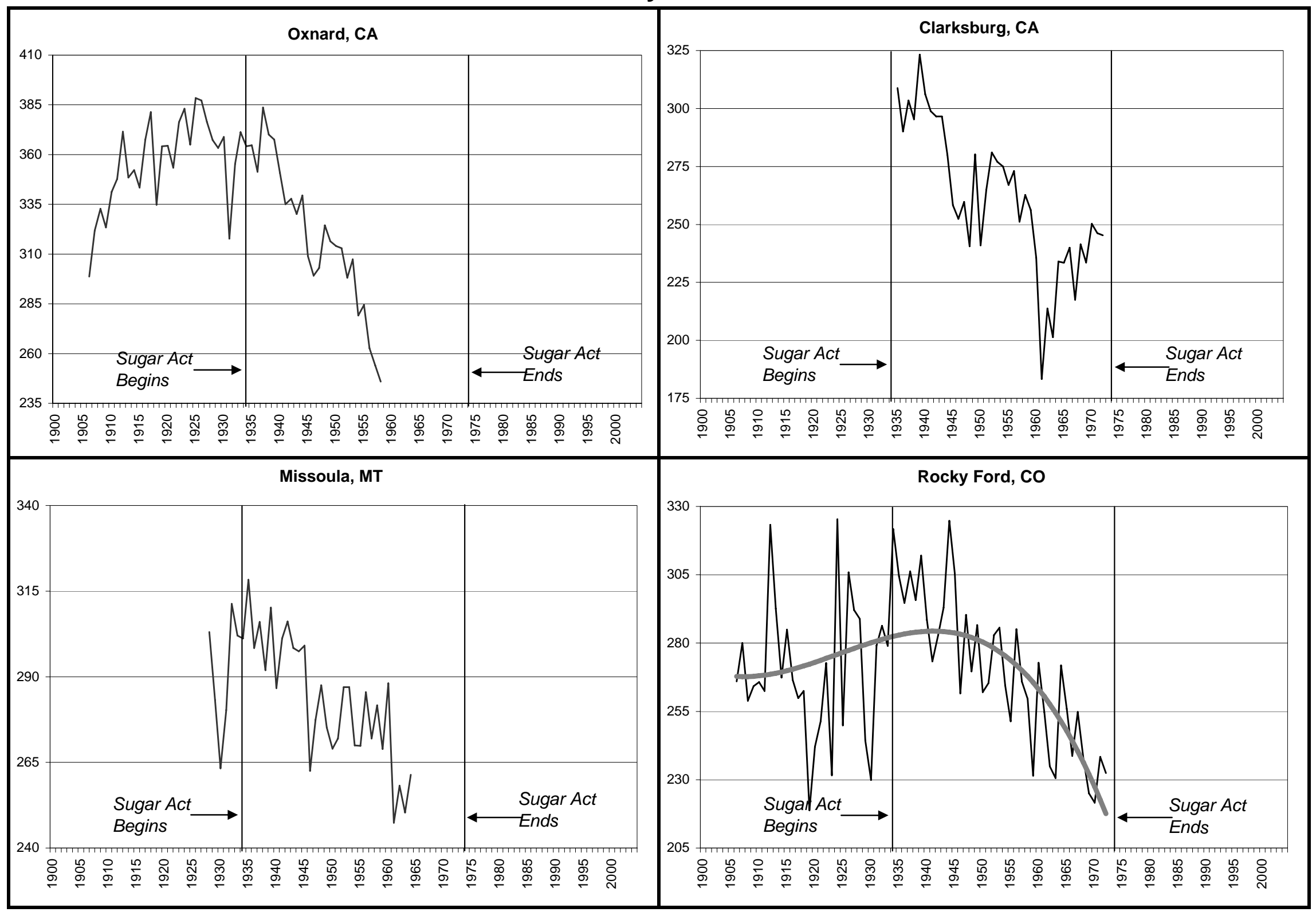


Figure 6B

Pounds of Manufactured-Sugar Per Ton of Purchased Beets

(Recovery Rate)

American Crystal Factories

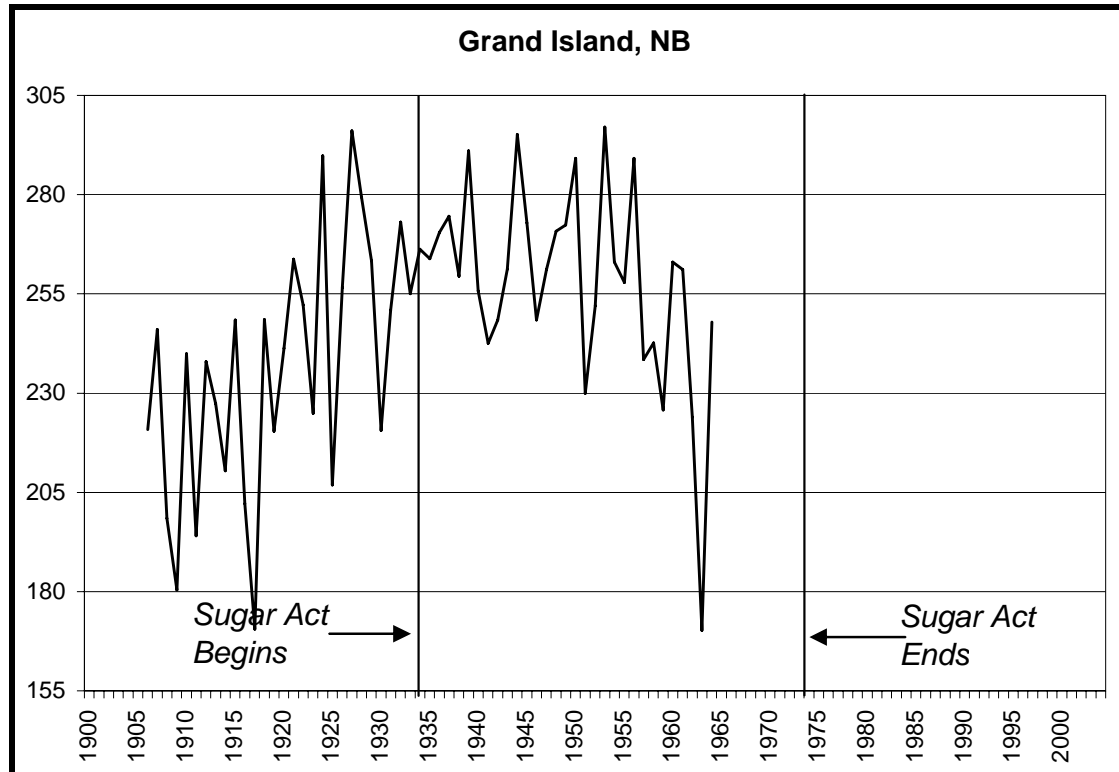

Mason City, IA

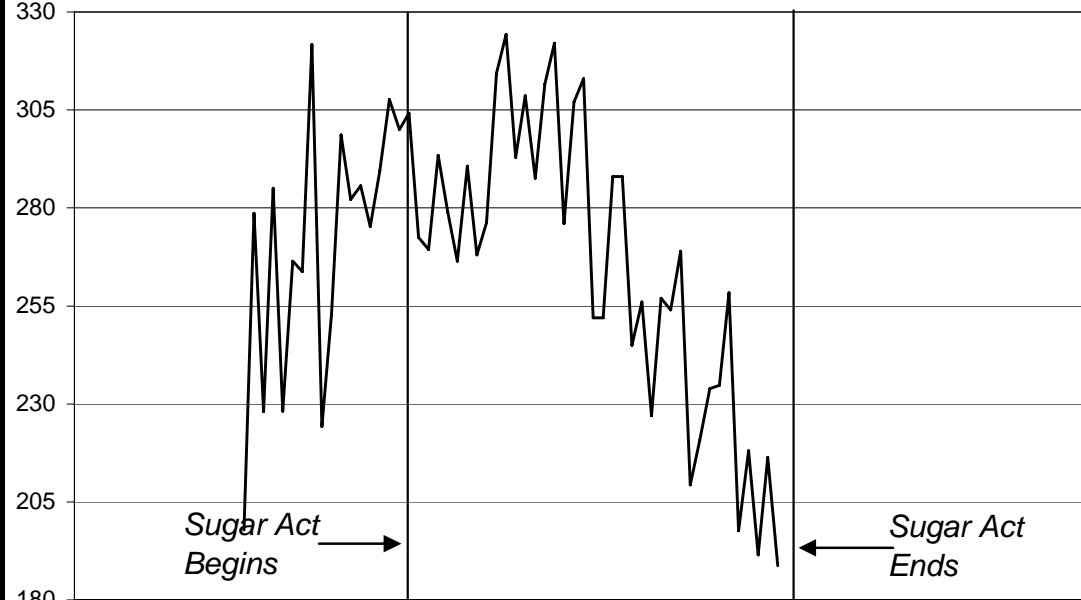

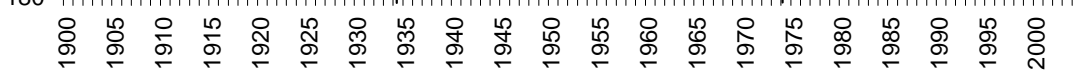

East Grand Forks, MN

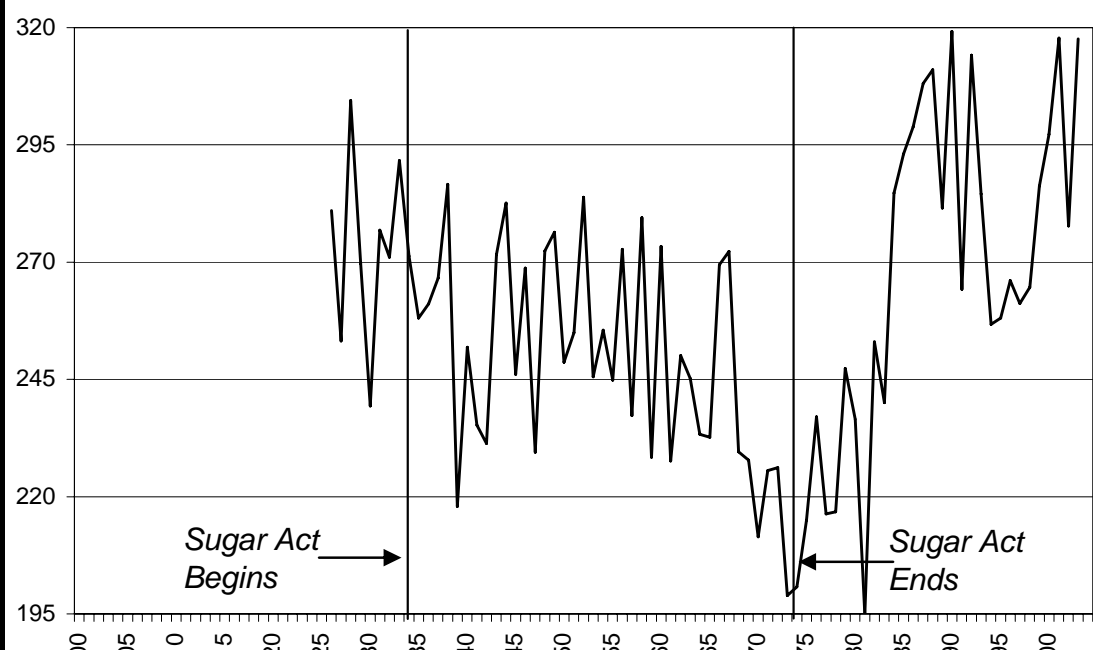

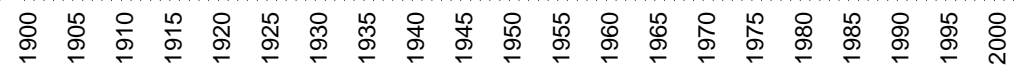

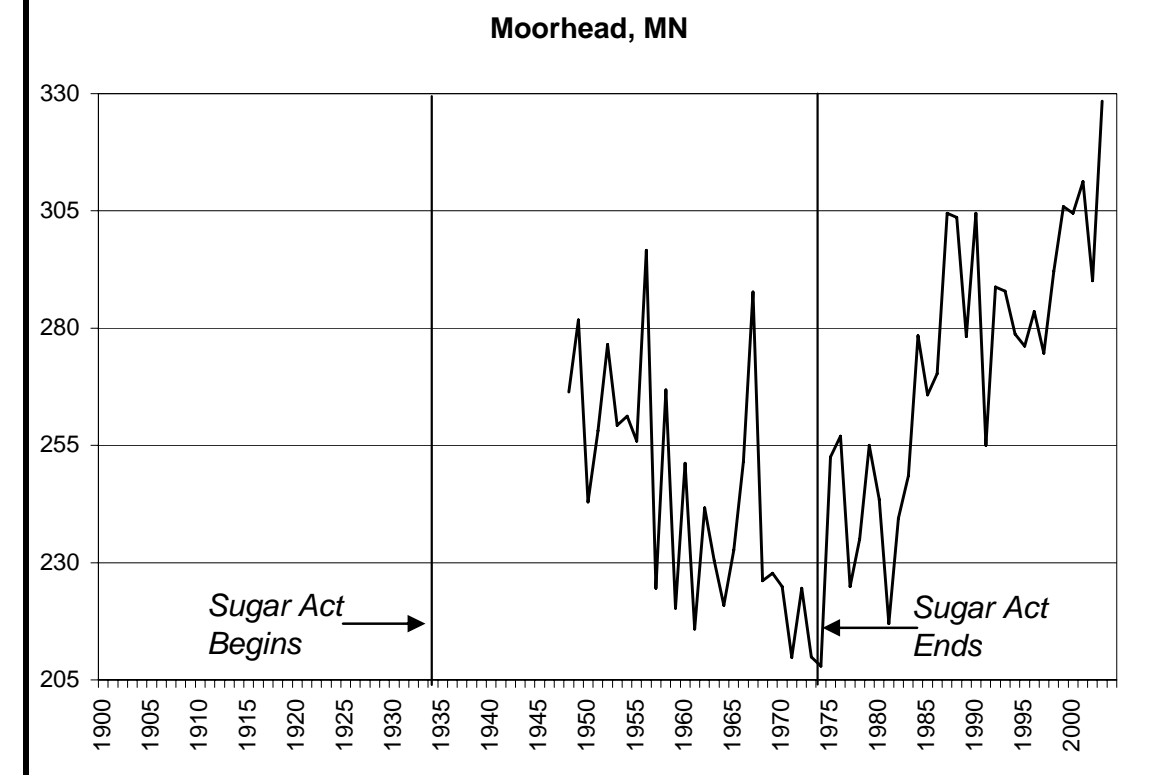


Figure 6C

Pounds of Manufactured-Sugar Per Ton of Purchased Beets

(Recovery Rate)

American Crystal Factories

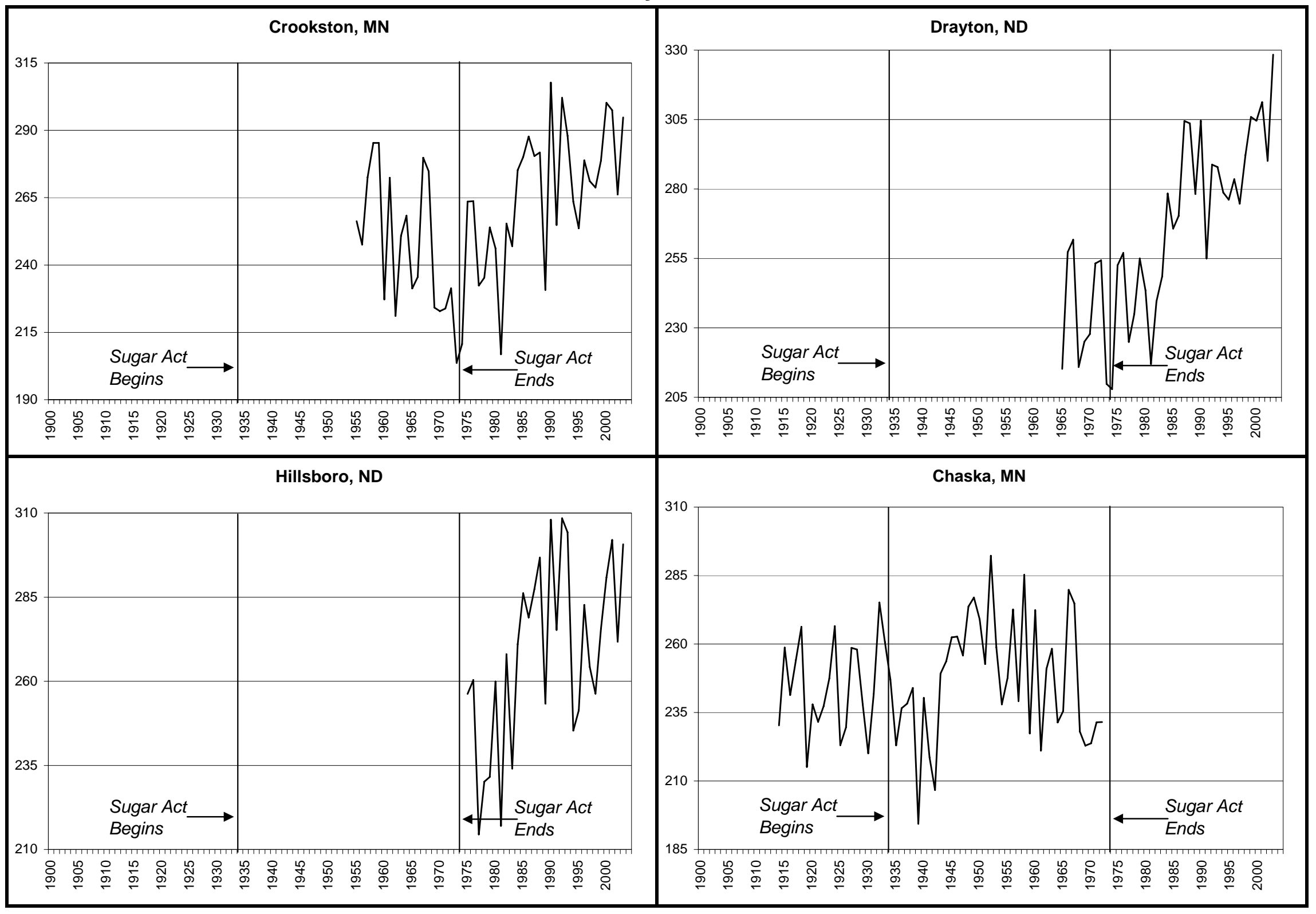




\section{Diagram 1}

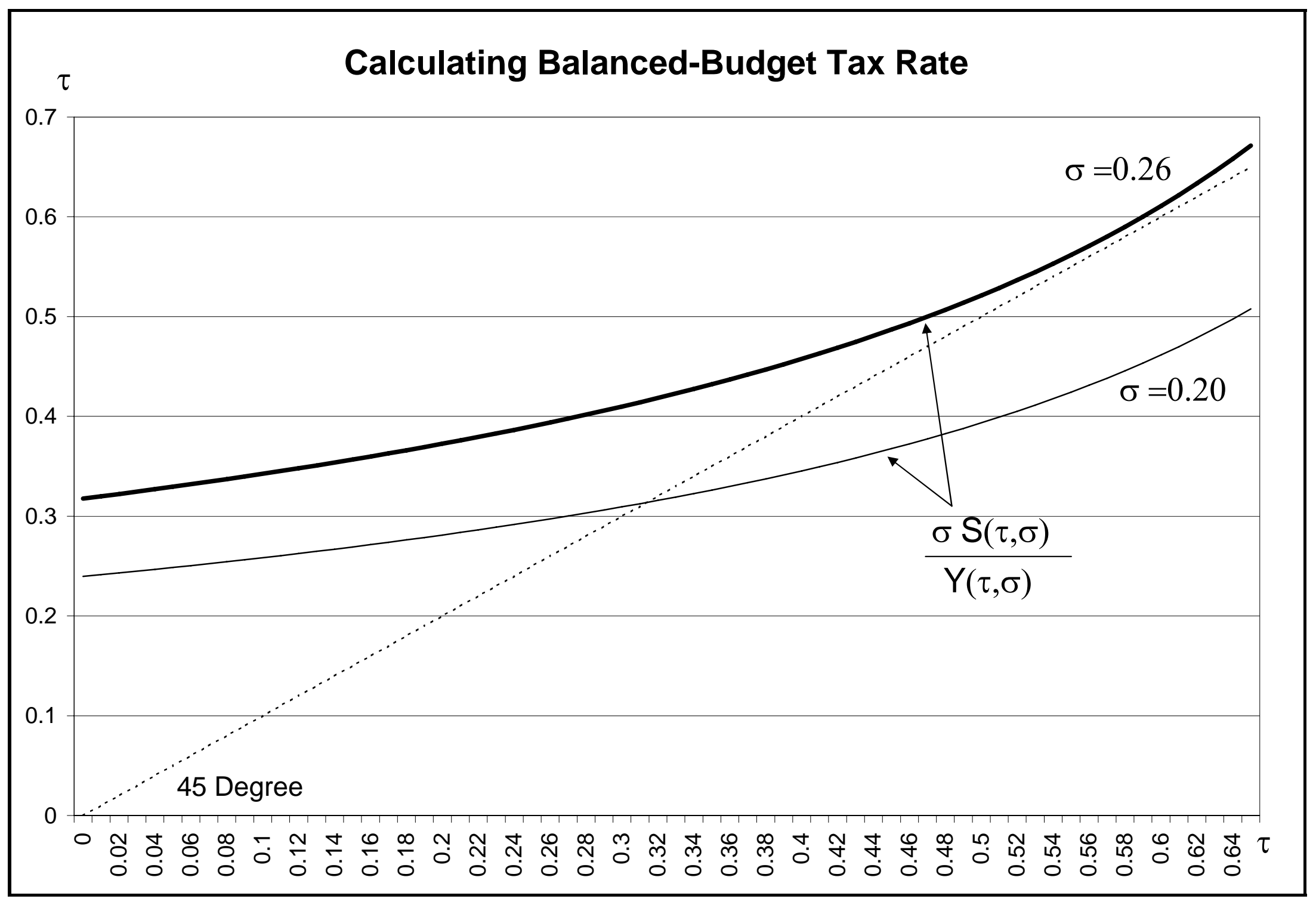

Tax Rate on Final Output 


\section{Diagram 2}

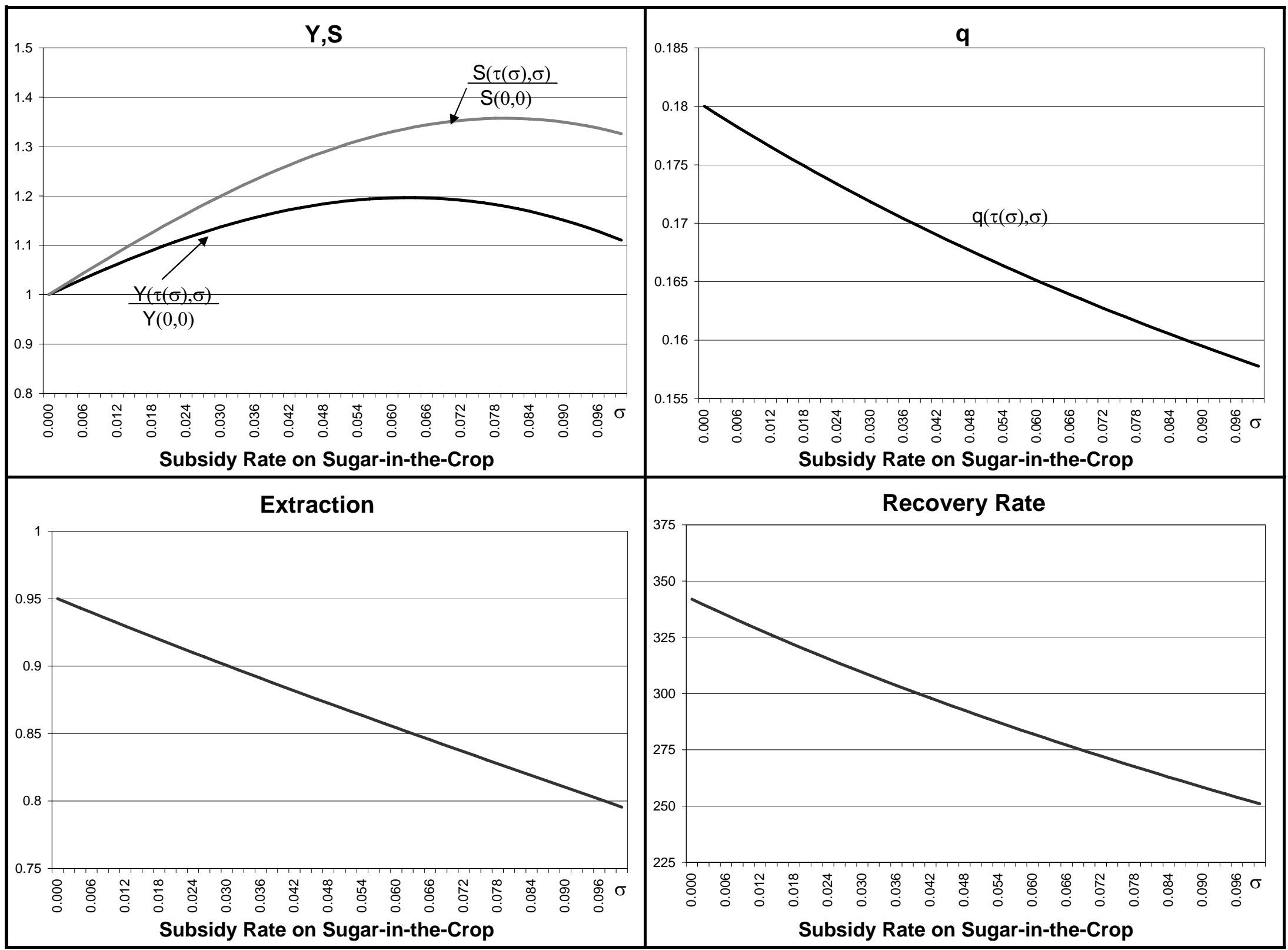


Diagram 3

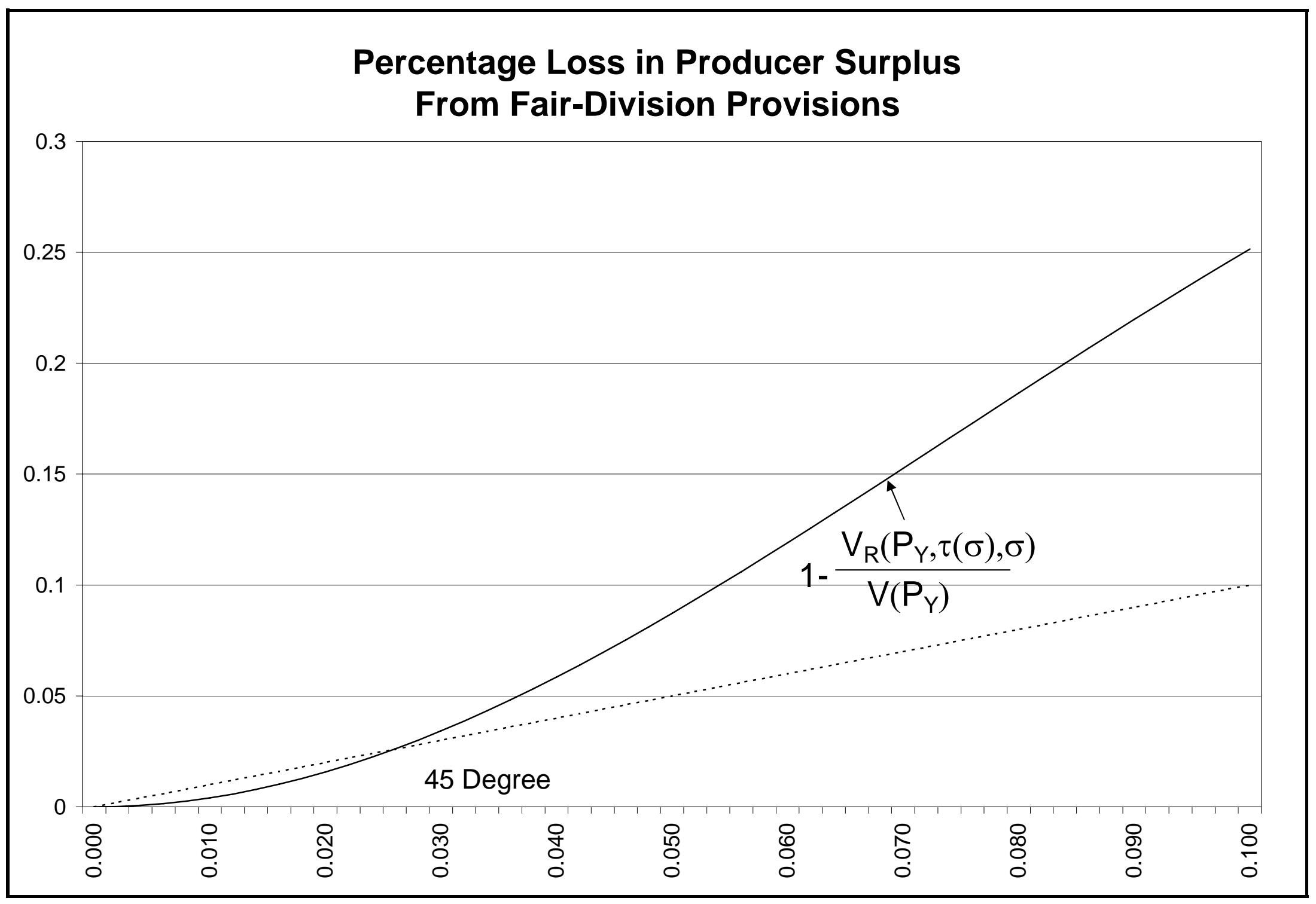

Subsidy Rate on Sugar-in-the-Crop 